\title{
ANALYSIS OF PISTON OF TWO STROKE ENGINE
}

\author{
S. Bhattacharya ${ }^{1}$, A. Basu ${ }^{2}$, S. Chowdhury ${ }^{3}$, Y.S. Upadhyaya ${ }^{4}$ \\ ${ }^{l}$ B.E Student, Department of Mechanical Engineering, Manipal Institute of Technology, Manipal, Karnataka, India \\ ${ }^{2}$ B.E Student, Department of Mechanical Engineering, Manipal Institute of Technology, Manipal, Karnataka, India \\ ${ }^{3}$ B.E Student, Department of Mechanical Engineering, Manipal Institute of Technology, Manipal, Karnataka, India \\ ${ }^{4}$ Associate Professor, Department of Mechanical Engineering, Manipal Institute of Technology, Manipal, Karnataka, \\ India
}

\begin{abstract}
Due to the inherent nature of combustion in the Cylinder of a Conventional Internal combustion engine, stress variation as well as a certain temperature distribution sets up in the entire piston. Analysis of piston is required because of its shape and it is subjected to both structural and thermal loads. In the present study, piston of a two stroke spark ignition internal combustion engine having maximum power of $6.5 \mathrm{~kW}$ at $5500 \mathrm{RPM}$, has been designed and analysed. The piston made up of Aluminium 4032 alloy is designed by conventional approach and then both thermal and transient structural analysis have been carried out.The piston has been modeled in CATIA and analysed using ANSYS Workbench. In order to improve the design of piston, two alternative designs have been considered by providing openings at the skirt region of the piston. The analysis showed that this modification improved the thermal performance of the piston. An alternative design with large openings at the skirt region showed the best thermal performance.
\end{abstract}

Keywords: Piston, Aluminum 4032, structural analysis, thermal analysis.

\section{INTRODUCTION}

Piston, a component of reciprocating engines, reciprocating pumps, gas compressors and pneumatic cylinders, is the moving component that is contained by a cylinder. In an Internal Combustion (IC) engine, it is acted upon by the pressure of the expanding combustion gases in the combustion chamber and the motion is transmitted to through the piston-connecting rod assembly to the crankshaft. A piston is a major component in an IC engine and its design/analysis is based on structural and thermal considerations. Gudimetal and Gopinath[1] successfully used reverse engineering to generate a CAD model of a damaged IC engine piston and using finite element method carried out a linear static and a coupled thermal-structural analysis. They concluded that reverse engineering could be used in conjunction with finite element analysis to model and re-model obsolete product geometries to suit with present demands. The use of the Computer Aided Modelling software CATIA is also attributed to the design of an IC engine component viz. piston as shown by Rajan et al.[2]. According to them, by altering the design parameter e.g. thickness of the crown, barrel thickness, thickness of the ring lands, an optimal solution to the existing design could be obtained.

Parra[3] showed that the empirical correlations to calculate the gas-side heat transfer coefficient, could be evaluated on a comparative basis using data from a current production diesel engine. Jeong[4] showed that the increase of copper and nickel content resulted in the finer microstructure and uniform precipitation. Also the thermal expansion coefficient was reduced and the elastic modulus, hardness, tensile strength were increased with the increase of copper and nickel content at high temperature. As shown by Mon et al.[5] by the aid of finite element method, thermal effect in the combustion chamber is influenced by major parameters such as combustion flame temperature, convection of cooling system, thermal properties of engine component materials. It was also found that the choice of material for the component in the combustion chamber is one of the solutions, in order to improve engine performance. Besides, the geometry and dimension of the engine parts are also considered in order to improve the engine performance.

The objective of the present study focusses on the design and analysis of the piston based on the structural and thermal considerations. The use of computational fluid dynamics and generation of a combustion model, as carried out by Toppo[6], has limited application in this analysis. Also, the secondary lateral motion, considered by Kuppast et al.[7], is not taken into account.

\section{PISTON AND ITS MATERIAL}

The piston considered for the present study is of a 2 stroke single cylinder petrol engine. The engine specifications are shown in Table 1. The most common material used for automotive pistons is aluminum due to its light weight, low cost, and acceptable strength. Although other elements are present in smaller amounts, the alloying element of concern is silicon in aluminum pistons. Using an alloy having a composition beyond the eutectic point i.e., more than $12 \%$ $\mathrm{Si}$, offers lower coefficient of thermal expansion, and therefore, engine designers are permitted to specify much tighter tolerances. Due to pistons intricate structure, the use of hyper-eutectic composition of silicon is justified, since it increases the fluidity or the viscosity of the molten 
aluminum used [8]. However, adding silicon to pistons makes them more brittle and thus making the piston more susceptible to cracking if the engine experiences pre-ignition or detonation.

Table 1: Specification of single cylinder 2 stroke petrol engine

\begin{tabular}{|l|l|}
\hline Displacement volume & $145.45 \mathrm{cc}$ \\
\hline Clearance volume & $\sim 30 \mathrm{cc}$ \\
\hline Stroke length & $57 \mathrm{~mm}$ \\
\hline Bore diameter & $57 \mathrm{~mm}$ \\
\hline Compression ratio & 5.8 \\
\hline Maximum power & $6.5 \mathrm{~kW}$ at $5500 \mathrm{rpm}$ \\
\hline Maximum torque & $11.3 \mathrm{Nm}$ at $4000 \mathrm{rpm}$ \\
\hline
\end{tabular}

These problems are addressed by using a Al-Si alloy i.e., Al 4032 grade alloy as thepiston material. This piston material has a silicon content of approximately $12 \%$. Composition of Al 4032 grade is shown in Table 2. Mechanical properties of Al 4032 grade aluminum the material are also shown in Table 3.

Table 2: Composition of $\mathrm{Al} 4032$ grade aluminum alloy

\begin{tabular}{|l|l|}
\hline Material & \% by weight \\
\hline Aluminium & 85 \\
\hline Silicon & 12.20 \\
\hline Copper & 0.9 \\
\hline Magnesium & 1.0 \\
\hline Nickel & 0.9 \\
\hline
\end{tabular}

Table 3: Mechanical properties of Al-4032 grade aluminum alloy

\begin{tabular}{|l|l|}
\hline Properties & Value \\
\hline Density & $2690 \mathrm{~kg} / \mathrm{m}^{3}$ \\
\hline Poisson's Ratio & 0.33 \\
\hline Elastic Modulus & $70-80 \mathrm{GPa}$ \\
\hline Tensile Strength & $380 \mathrm{MPa}$ \\
\hline Hardness & $120 \mathrm{HB}$ \\
\hline Shear Strength & $260 \mathrm{MPa}$ \\
\hline Fatigue Strength & $110 \mathrm{MPa}$ \\
\hline Thermal Expansion Coefficient & $19.4 \times 10^{-6} /{ }^{\circ} \mathrm{C}$ \\
\hline Thermal Conductivity & $155 \mathrm{~W} / \mathrm{mK}$ at $35^{\circ} \mathrm{C}$ \\
\hline
\end{tabular}

\section{DESIGN OF PISTON ASSEMBLY}

A piston must be designed to withstand the damage caused by the extreme heat and pressure of combustion process, the gas forces and inertia forces. In addition, it should be designed as an effective sealant to prevent engine oil from entering the combustion chamber and the combustion gases from entering the engine crankcase (blow-by gases). The piston designed should be rigid enough to prevent mechanical and thermal distortion and it should have sufficient bearing area to prevent undue wear. The strength of the piston pin should be sufficient against shear failure. The piston is designed based on both strength and thermal considerations. Preliminary dimensions of piston have been determined using the strength and thermal based design approach [9]. This has resulted in piston diameter of $56 \mathrm{~mm}$, piston length of $60 \mathrm{~mm}$ and piston pin diameter of $15 \mathrm{~mm}$. The design considers three piston rings. The model of the designed piton is shown in Fig. 1.

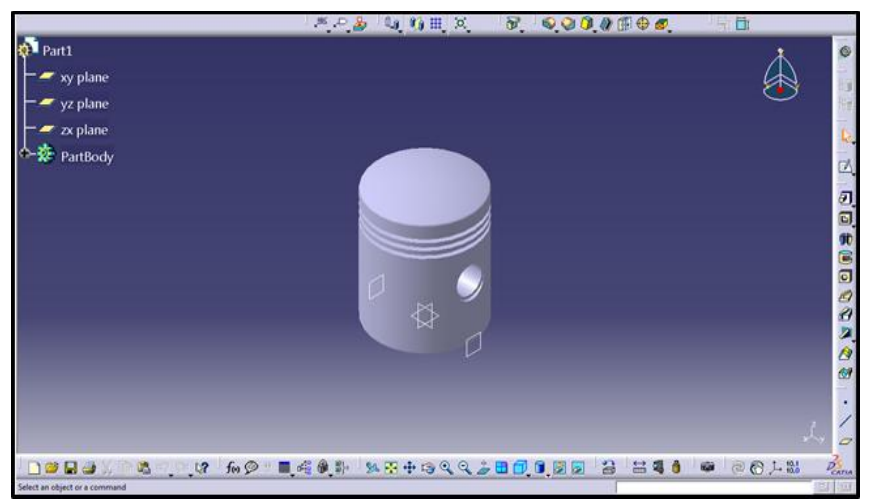

Fig 1: Model of the piston

\section{ANALYSIS OF THE PISTON}

\subsection{Structural Analysis}

During combustion process, the force is transmitted through the piston to the gudgeon pin. In addition the piston also suffers from a shock loads due to combustion. The piston is designed to withstand the shock loads and with repeated cycles or transient loading, it would not undergo fatigue failure. The gudgeon pin (which connects the piston to the connecting rod in a conventional internal combustion engine) is subjected to a combination of shearing and bending loads. At the time of combustion, the piston is subjected to distortion and the energy stored inside the piston serves as a determining factor to know the yield and failure conditions of a piston when subjected to static loading. Von Mises yield criterion can be formulated in terms of the von Mises stress or equivalent tensile stress, $\sigma_{v}$, a scalar stress value that can be computed from the stress tensor as shown in eq. 1 [10]. In this case, a material is said to start yielding when its von Mises stress reaches a critical value known as the yield strength, $\sigma_{\mathrm{y}}$ as shown in eq $-(1)$;

$$
\begin{aligned}
& \sigma_{v}^{2}=\frac{1}{2}\left[\left(\sigma_{11}-\sigma_{22}\right)^{2}+\left(\sigma_{22}-\sigma_{33}\right)^{2}+\left(\sigma_{11}-\sigma_{33}\right)^{2}+\right. \\
& \left.6\left(\sigma_{23}^{2}+\sigma_{31}^{2}+{\sigma_{31}}^{2}\right)\right]
\end{aligned}
$$

In this analysis, an attempt has been made to calculate pressure and acceleration values at specific time within the cycle, and thereby simulating the working condition. Although this analysis isn't accurate, the obtained results are comparable to the actual stress and deformation values. Illánet. al[11] expressed boundary conditions as set equations and then converted it into an electrical circuit with capacitors and solved it using P-Spice. In accordance with the above findings, a plot of the pressure distribution with respect to time was obtained for a complete half cycle as shown in Fig 2. Acceleration of piston has been derived 
assuming no failure of the components and uniform angular velocity of the crank. Using the piston motion equation, the variation of acceleration w.r.t. crank angle can be found out. Distribution of acceleration on piston crown is shown in Fig. 2.

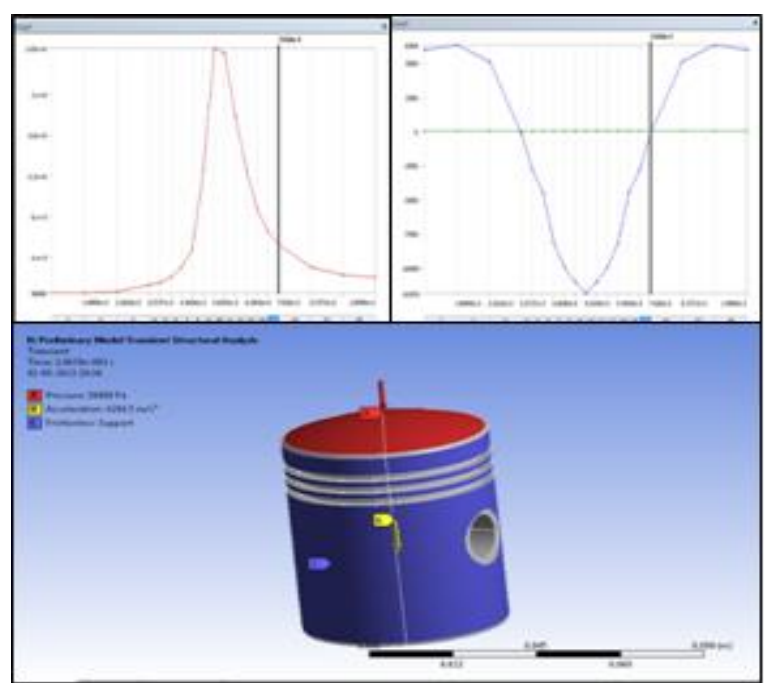

Fig-2: Distribution of pressure and acceleration on the piston

\subsection{Thermal Analysis}

Most of the IC engine pistons are made of an aluminum alloy which has a thermal expansion coefficient value at $80 \%$ higher than the cylinder bore liner material made of cast iron [12]. This leads to some differences between running and the design clearances. Due to the design consideration, the highest temperature at any point in piston must not exceed more than $60 \%$ of the melting point temperature of the alloy, because the alloy subjected to higher temperature undergoes change in the crystal structure which seriously hampers the long-run operation of the piston. Heat transfer coefficients for different surfaces of the piston were estimated.

For the simplicity of calculations it is assumed that at high temperature the combustion (flue) gases behave as ideal gases. The boundary conditions are evaluated as convection coefficients under two categories i.e.

- Heat transferred from the combustion gases to the piston crown.

- Heat transferred to the engine motor oil from the body of the piston.

In the former category, viz. heat transferred to the piston crown, from the gases to the metal, heat is transferred mainly by forced convection with a contribution by radiation. Radiative contribution is more significant in compression-ignition engines than in spark-ignition engines, due to the formation of highly radiative soot particles during combustion. Assuming the flow of the combustion gases to be over a flat plate, the correlation of convection used, based on fully turbulent flow over flat plate is shown in eq- (2).

$$
N u=0.037(R e)^{0.8}(P r)^{0.33}-(2)
$$

\section{Re- Reynolds Number \\ Pr- Prandtl Number \\ $\mathrm{Nu}$ - Nusselts Number}

Many correlations were developed by various researchers to estimate the convective heat transfer coefficient in various cases. In engines, there are parts which move against each other causing friction which is responsible for loss of power due to conversion of energy into heat. Contact between moving surfaces also wears away those parts, which could lead to lower efficiency and degradation of the engine. This increases fuel consumption, decreases power output and can lead to engine failure. Lubricating oil creates a separating film between surfaces of adjacent moving parts to minimize direct contact between them, decreasing heat caused by friction and reducing wear, thus protecting the engine. In use, motor oil transfers heat through convection as it flows through the engine. The basic heat transfer correlation used based on turbulent flow over a cylinder isshown in eq- (3)

$N u=C R e^{m} \operatorname{Pr}^{0.333}$

Where the value of ' $C$ ' and ' $m$ ' depends on the value of the Reynolds number of flow of the motor oil.

\section{RESULTS AND DISCUSSION}

\subsection{Preliminary Design}

From the analysis of preliminary design, the temperature obtained at the piston region is shown in Table 4(a). Maximum temperature is observed at the center of crown due to the maximum heat transfer occurs over a smaller area due to curved surface of the piston crown where compression ratio of the gases is maximum. Also at that region, its thickness is small and it experiences maximum heat. Though the piston is subjected to relatively a lower value of stress, but the deflection observed is quite high as shown in Table 4(b). Fig. 3 shows the distribution of stress, deflection and temperature in piston. By observing the lower portion of the piston, the values of stress, deflection and temperature are on lower side and therefore there is scope for improvement.

Table 4(a): Results of Thermal analysis of preliminary design

\begin{tabular}{|l|l|l|l|l|}
\hline Design & Mass $(\mathrm{kg})$ & $\begin{array}{l}\text { Maximum } \\
\text { temperature }\left({ }^{\circ} \mathrm{C}\right)\end{array}$ & $\begin{array}{l}\text { Variation in temperature at } \\
\text { thegudgeon pin region }\left({ }^{\circ} \mathrm{C}\right)\end{array}$ & $\begin{array}{l}\text { Temperature variation in the } \\
\text { skirt region }\left({ }^{\circ} \mathrm{C}\right)\end{array}$ \\
\hline $\begin{array}{l}\text { Preliminary } \\
\text { design }\end{array}$ & 0.21 & 357 & $\begin{array}{l}\text { Major variation at the top and } \\
\text { bottom }\end{array}$ & $180-230$ \\
\hline
\end{tabular}


Table 4(b): Results of Structural analysis on Preliminary Design

\begin{tabular}{|l|l|l|l|}
\hline Design & $\begin{array}{l}\text { Mass } \\
(\mathrm{kg})\end{array}$ & $\begin{array}{l}\text { Maximum stress } \\
(\mathrm{MPa})\end{array}$ & $\begin{array}{l}\text { Maximum deflection } \\
(\mathrm{mm})\end{array}$ \\
\hline Preliminary design & 0.21 & 21.4 & 10.9 \\
\hline
\end{tabular}

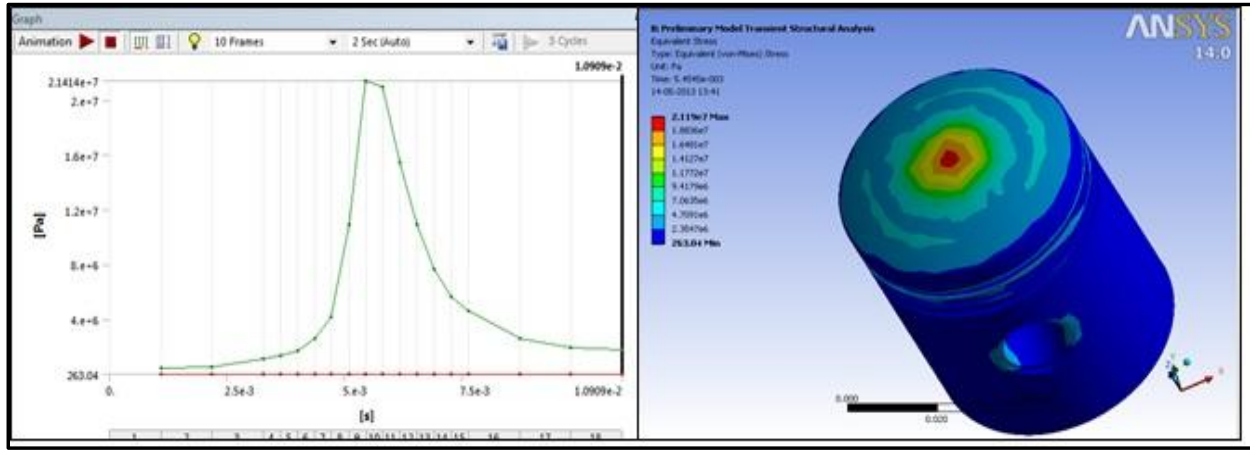

Fig 3(a): Von Mises Stress distribution
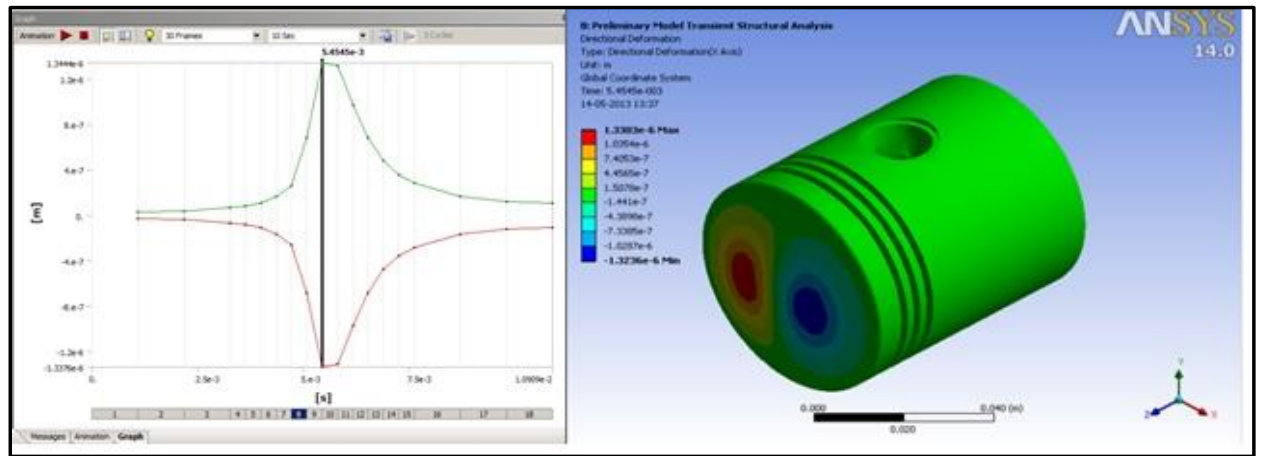

Fig 3(b): Deformation distribution

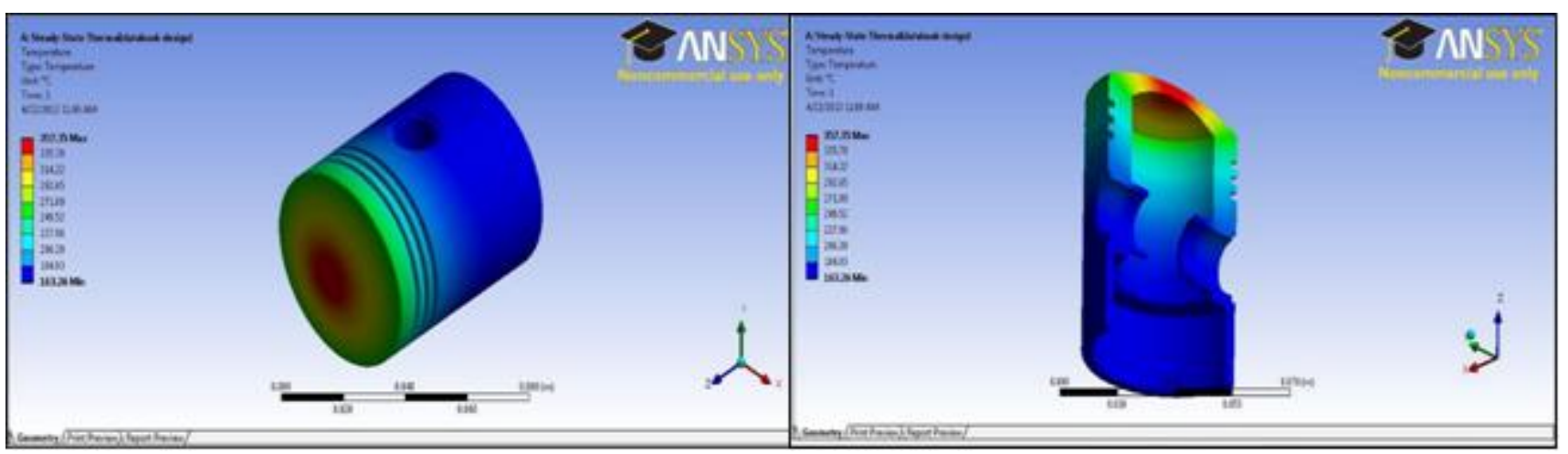

Fig 3(c): Temperature profile of the piston

\subsection{Analysis of Alternatives}

The results of finite element analysis carried out have depicted a certain specific set of observations which do not comply with recent design standards of pistons used in automobile design. Firstly, for the prescribed operating temperature, peak temperature from the combustion of gas in the chamber, the maximum temperature occurs on the piston crown which is $357{ }^{\circ} \mathrm{C}$ as shown in Fig. 3(c). According to the design standards of the piston, the maximum temperature must not exceed $60 \%$ of the melting point of the alloy used which is approximately $360^{\circ} \mathrm{C}$. Therefore, further improvement of the design is needed.
Secondly, there is a significant difference in temperatures between the upper and lower surfaces of the gudgeon pin bearing which causes unequal expansion and hence thermal stresses may develop which is not recommended. Thirdly, analyzing the results of transient structural analysis, there is a sharp change in deformation and Von Mises Stress in the cycle during the operation of the engine as shown Fig 3(a). Considering the above, alternate design of piston was taken up and two such alternatives have been shown in Fig. 4. A comparison of result analysis of alternative designs with the preliminary designs is also shown in Table 5 below. 


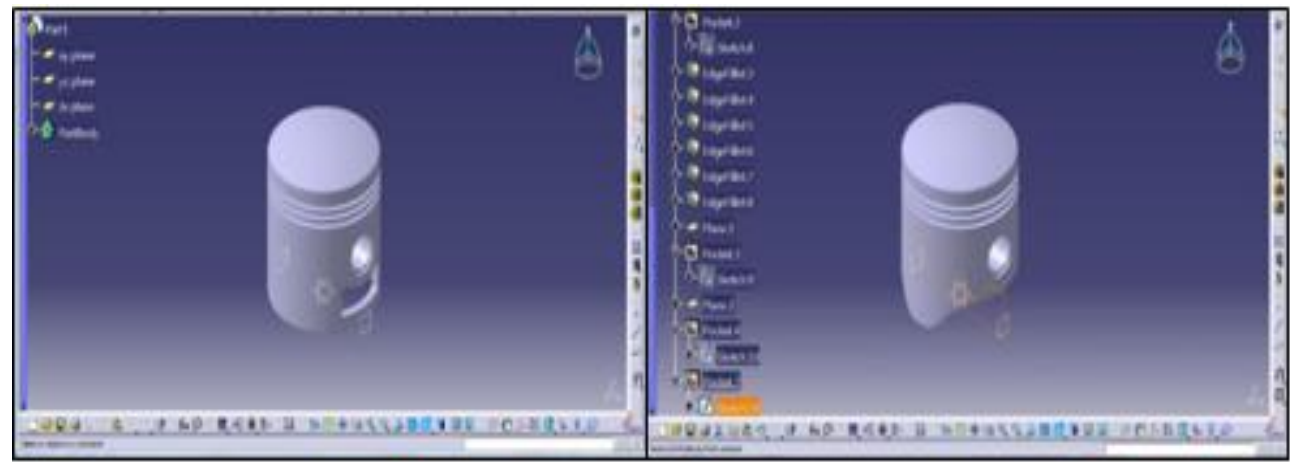

(a) Alternate design-1

(b) Alternate design -2

Fig. 4: Alternative Designs

Table 5(a): Comparison of Thermal analysis results of alternative designs and preliminary design

\begin{tabular}{|l|l|l|l|l|}
\hline Design & $\begin{array}{l}\text { Mass } \\
(\mathrm{kg})\end{array}$ & $\begin{array}{l}\text { Maximum temperature } \\
\text { attained }\left({ }^{\circ} \mathrm{C}\right)\end{array}$ & $\begin{array}{l}\text { Temperature variation in the } \\
\text { gudgeon pin region }\left({ }^{\circ} \mathrm{C}\right)\end{array}$ & $\begin{array}{l}\text { Variation } \\
\text { temperature in of } \\
\text { skirt }\left({ }^{\circ} \mathrm{C}\right)\end{array}$ \\
\hline Preliminary Design & 0.21 & 357 & Negligible & $180-230$ \\
\hline Alternative - 1 & 0.207 & 335 & Negligible & $180-230$ \\
\hline Alterative - 2 & 0.19 & 339 & Negligible & $180-230$ \\
\hline
\end{tabular}

Table 5(b): Comparison of structural analysis results of alternative designs and preliminary designs

\begin{tabular}{|l|l|l|l|l|}
\hline Design & $\begin{array}{l}\text { Mass } \\
(\mathrm{kg})\end{array}$ & $\begin{array}{l}\text { Maximum stress } \\
(\mathrm{MPa})\end{array}$ & $\begin{array}{l}\text { Maximum deflection } \\
(\mathrm{mm})\end{array}$ & $\begin{array}{l}\text { Minimum defection } \\
(\mathrm{mm})\end{array}$ \\
\hline Preliminary Design & 0.21 & 21.4 & 10.91 & 2.07 \\
\hline Alternative 1 & 0.207 & 27.7 & 10.91 & 2.46 \\
\hline Alternative 2 & 0.19 & 22.7 & 10.91 & 2.34 \\
\hline
\end{tabular}

The analysis results in terms of von Mises stress, deformation and temperature distribution for both Alternative design 1 and Alternative design 2 are shown in Fig. 5 and Fig. 6 respectively. The results show a decrease in piston temperature compared to the preliminary design. On the basis of the preliminary data compiled and subsequent thermal and structural analysis shows that, reduction in the skirt of the piston significantly improve the thermal aspects of design rather the structural aspects. In the present case, the maximum temperature at the piston crown was reduced to prevent subsequent crystallization of the surface of the piston. A further detailed investigation into the temperature variation at the gudgeon pin region as well as at the skirt, shows minor changes in variation in the two designs.

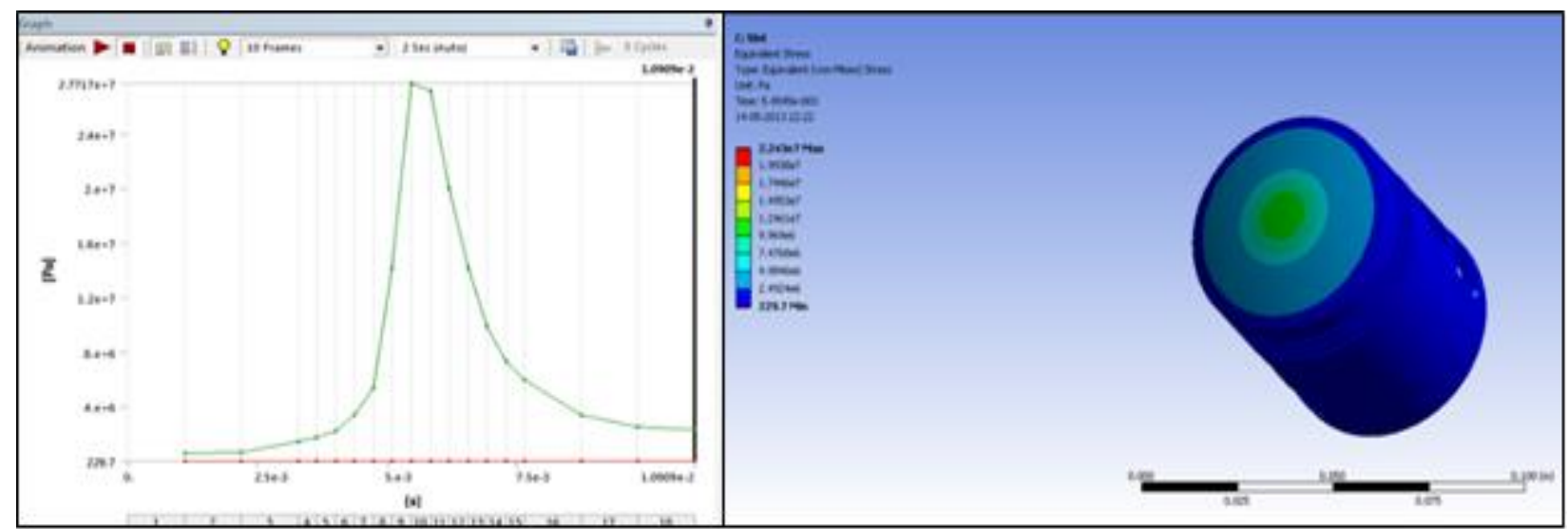

Fig 5(a): Von Mises stress distribution in Alternative design 1. 


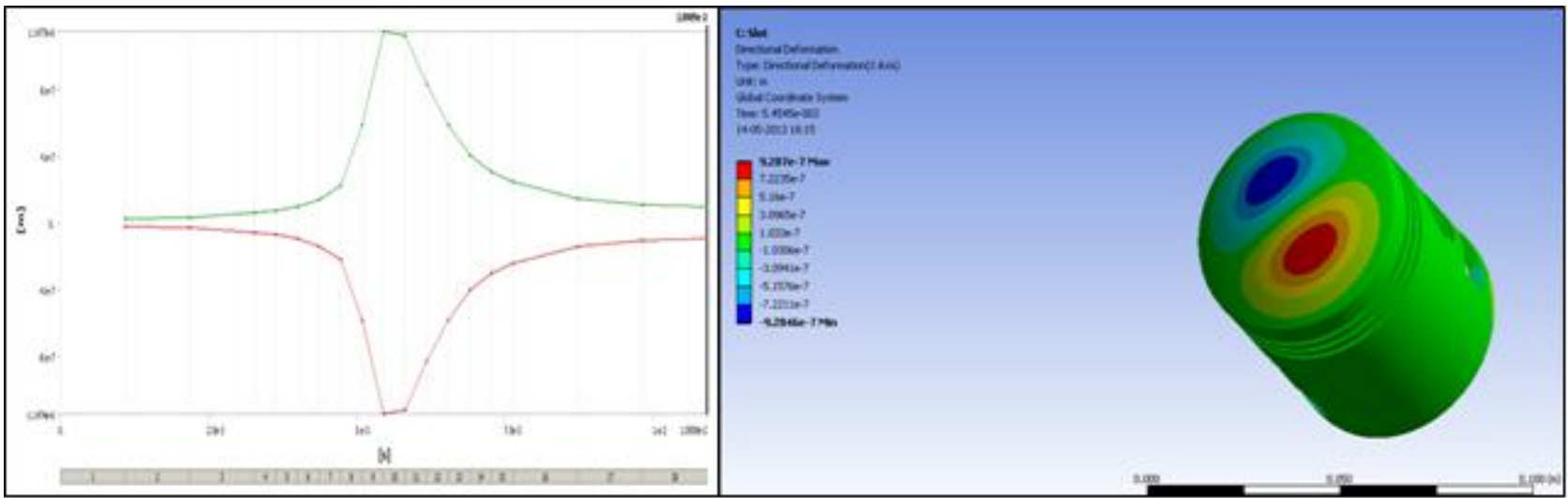

Fig. 5(b): Distribution of Directional Deformation at peak condition in Alternative design 1

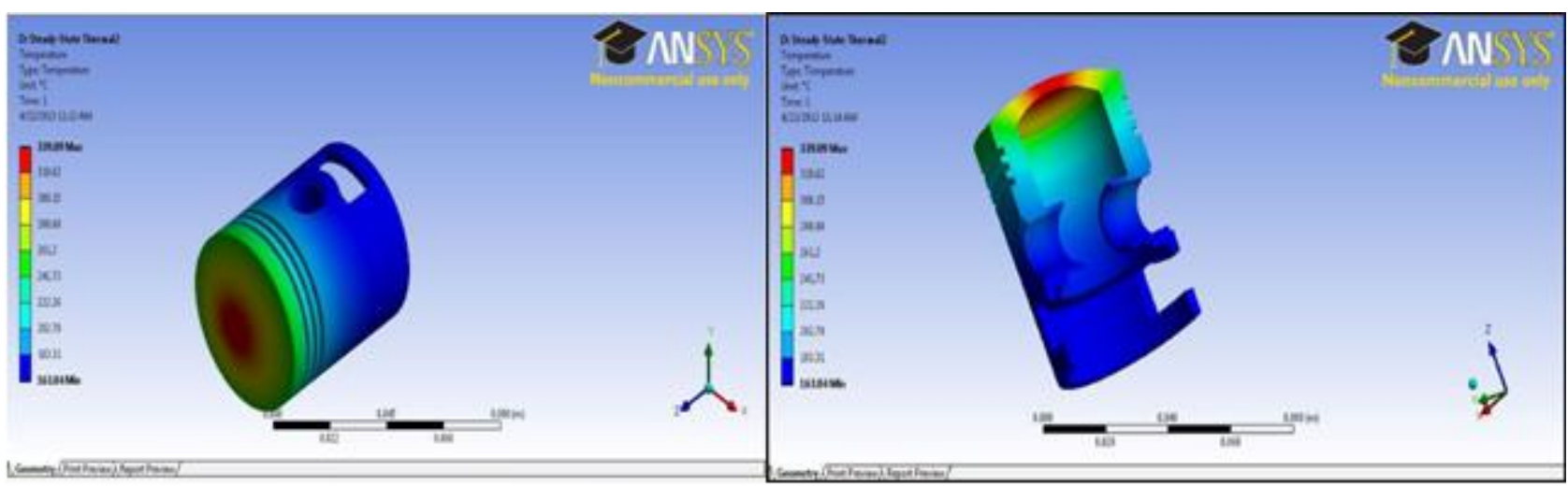

Fig. 5(c): Temperature distribution in Alternative design 1

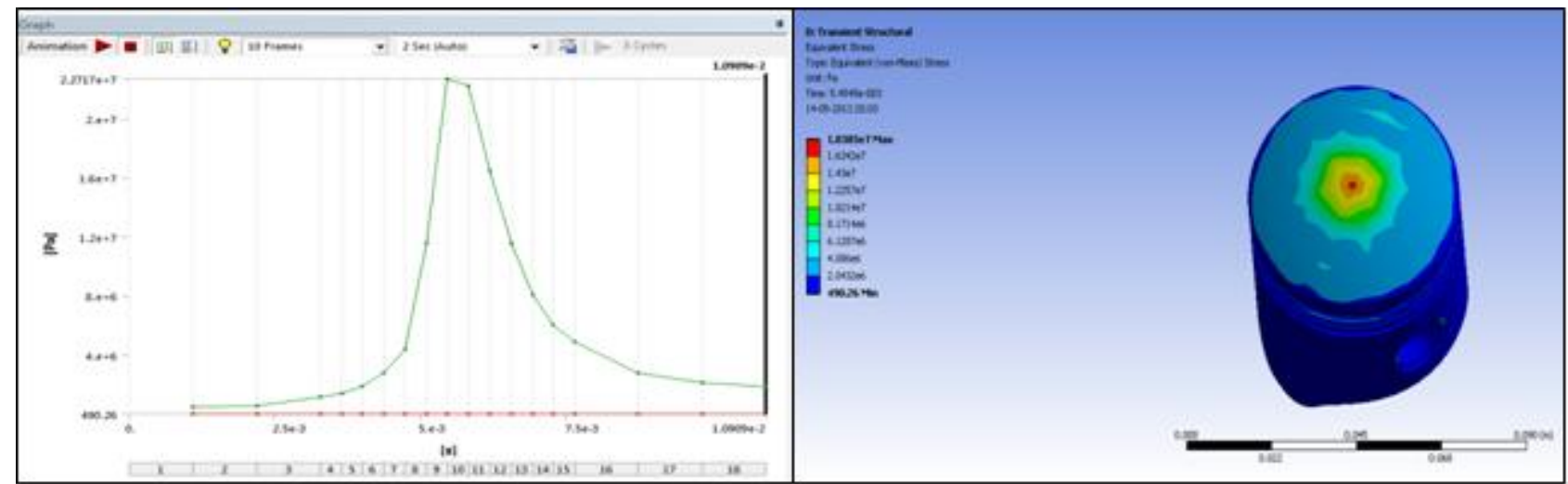

Fig. 6(a): Von Mises stress distribution in Alternative design 2

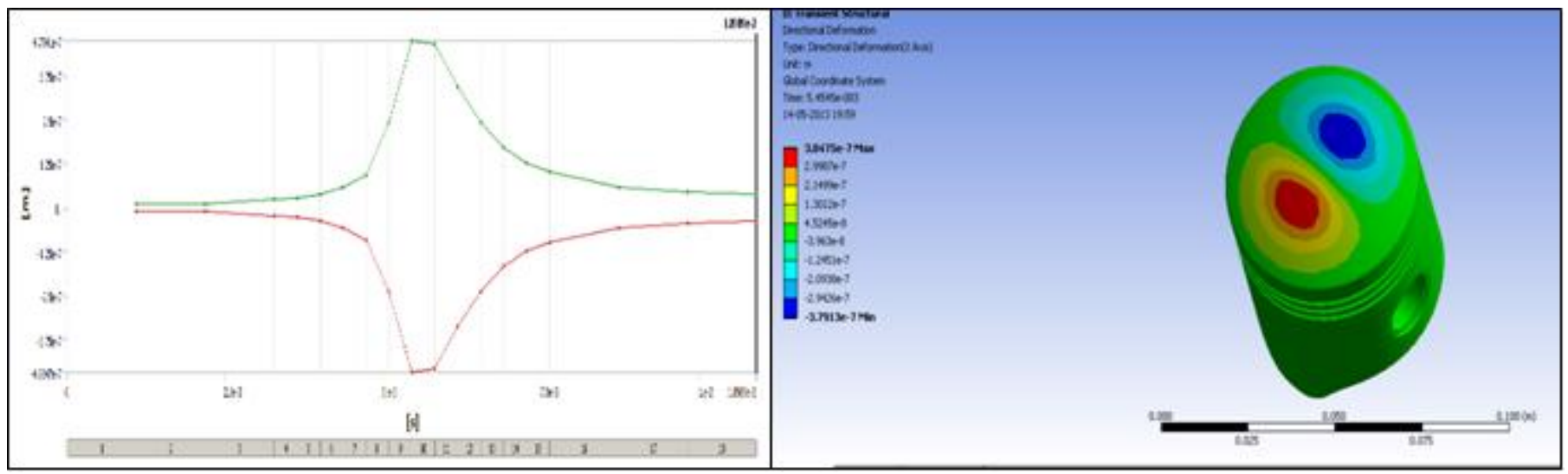

Fig. 6(b): Distribution of Directional Deformation at peak condition in Alternative design -2 


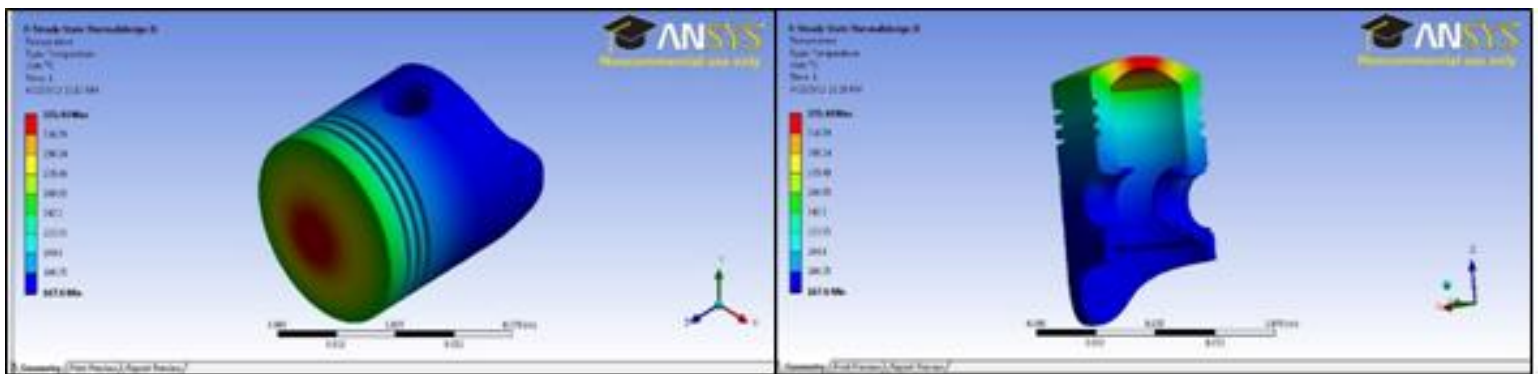

Fig. 6(c): Temperature distribution in Alternate design 2

\section{CONCLUSIONS}

Comparing the results of preliminary design and two alternative designs it is concluded that by modifying the skirt region thermal performance of the piston could be improved without a major change in structural performance. Piston mass could be reduced up to a limit, beyond which a further reduction would result in distortion of the piston. However, of the two alternative designs, the one with large openings in the skirt region (Alternative design 2) showed the best thermal performance. It is possible to further improve the analysis results by simulating the actual conditions using a combustion model of the engine.

\section{REFERENCES}

[1]. P Gudimetal and C V Gopinath, Finite Element Analysis of Reverse Engineered Internal Combustion Engine Piston, Asian International Journal of Science and Technology in Production and Manufacturing Engineering 2(4) 2009, 85-92.

[2]. Ch. V Rajan, P.V. K Murthy, M.V.S Murali Krishna and G.M. Prasada Rao, Design Analysis and Optimization of piston using Catia and Ansys,International Journal of Innovative Research in Science and Engineering, Issn 2319 -5665(January 2013, Issue 2 Volume1)

[3]. CA F Parra,Heat Transfer Investigations in a Modern Diesel Engine, A thesis submitted for the degree of Doctor of Philosophy,University of Bath, Department of Mechanical Engineering,February 2008.

[4]. CY Jeong, Effect of Alloying Elements on High Temperature Mechanical Properties for Piston Alloy, Department of Nuclear and Energy System Engineering, Dongguk University.

[5]. T.T.Mon, M.M.Noor, K.Kadirgama, R A.Bakar andM.F.Ramli, Finite Element Analysis on Thermal Effect of the Vehicle Engine,Proceedings of MUCEET: Malaysian Technical Universities Conference on Engineering and Technology, 2009

[6]. I O Toppo, CFD Analysis of combustion characteristics of Jathropha in compression ignition engine, Indian Institute of Science, Bangalore

[7]. V V. Kuppast, S.N.Kurbet, H.D.Umeshkumar an B C, Adarsh,Thermal Analysis of Piston for the

Influence on Secondary motion,International Journal of Engineering Research and Applications (IJERA);3 (3), May-Jun 2013

[8]. D. Apelian, Worldwide Report, Aluminum Cast Alloys: Enabling Tools for Improved Performance, NADCA, 2009
[9]. K. Mahadevan and L. B. Reddy, Design Data Handbook for Mechanical Engineers.

[10]. J E Shigley, Mechanical Engineering Design, McGraw Hill Book Company, 1986.

[11]. F. Illán, M. Alarcón, Numerical analysis of combustion and transient heat transfer processesin a two-stroke SI engine,Journal of Applied Thermal Engineering, 2010.

[12]. R.K Rajput, A Text book of Heat and Mass transfer 